* Doutor em Administração pela Escola Brasileira de Administração Pública e de Empresas da Fundação Getulio Vargas. Professor da Universidade Estadual do Maranhão. e-mail: gilsonmartins@ccsa.uema.br

** Doutora em Direito pela Universidade Federal de Santa Catarina. Professora do Programa de PósGraduação em Direito da PUC/PR. e-mail: kkozicki@uol.com.br

*** Doutorando em Direito Econômico e Social pela Pontifícia Universidade Católica do Paraná. Promotor de Justiça no Estado do Piauí. e-mail: coelhoslz@gmail.com

\section{O princípio da vulnerabilidade e as técnicas de neuromarketing: aprofundando o consumo como vontade irrefletida}

\author{
THE PRINCIPLE OF VULNERABILITY AND \\ NEUROMARKETING TECHNIQUES: DEEPER AS \\ CONSUMPTION WILL UNTHINKING
}

\author{
Gilson Martins Mendonça* \\ Katya Kozicki** \\ Sérgio Reis Coelho***
}

Resumo: Este artigo faz reflexão sobre o significado do neuromarketing e qual o impacto de suas técnicas no aprofundamento da vulnerabilidade do consumidor. Parte do princípio de que a legislação brasileira não se encontra ainda dotada de dispositivos aptos a proteger a vontade do consumidor quando esta esteja diante de técnicas que utilizem os conhecimentos do neuromarketing. Defende que a semelhança do que ocorre no campo da publicidade, sejam introduzidos no Código de Defesa do Consumidor ou em legislação apartada dispositivos sobre a matéria, sob pena da repercussão negativa na vulnerabilidade e na intimidade do consumidor.

Palavras-chaves: Direito do Consumidor. Vulnerabilidade. Neuromarketing.

Abstract: This article is a reflection about neuromarketing and the impact of their techniques to deepen the vulnerability of the consumer. We depart from the principle that the Brazilian legislation is not yet equipped with devices able to protect the consumer when it will be on techniques that use knowledge of neuromarketing. It is argued that, similarly to what occurs in the field of advertising, are introduced in the Code of Consumer Protection legislation or devices apart on the matter, failing that the indiscriminate use of these techniques reflected negatively on their own vulnerability and intimacy consumer.

Keywords: Consumer Law. Vulnerability. Neuromarketing. 


\section{INTRODUÇÃO}

De todos os adjetivos que se poderia valer um intérprete para caracterizar e definir a sociedade contemporânea, no intuito de oferecer uma visão geral de sua significação e abrangência, percebe-se que a noção de ser uma sociedade de consumo, por excelência, tem destaque e coloca em evidência um personagem típico deste momento histórico: o consumidor.

O consumo é uma realidade. Não há como evitá-lo, impedi-lo, fugir de sua força atrativa, negá-lo, pois desde o momento em que o indivíduo acorda e passa a realizar suas atividades, alimenta-se, exercita-se, desenvolve a sua rotina habitual, a qual vai findar com o apagar das luzes para o descanso noturno. Renovando o ciclo, consome produtos e serviços, permitindo afirmar que do berço ao túmulo todos são e serão consumidores.

Essa marcha é inexorável, pois decorrente da existência humana, e a abordagem aqui proposta não é de uma leitura existencialista ${ }^{1}$ do consumo, pela qual se poderia defender que toda a responsabilidade do ato de consumir reside no consumidor, tampouco uma visão liberal, que o compreende, tão somente, como um instrumento inserido na liberdade econômica, no livre mercado, expressão da igualdade perante a lei, mas, ao contrário, se advoga que o ato de consumir deve cumprir uma função social, o qual deve ser suavizado e tutelado pelo Estado. Esse processo de suavização e tutela do consumo implica em um papel ativo do Estado na proteção do consumidor, pelo qual são criadas regras claras para sua defesa e, principalmente, o reconhecimento legislativo da sua vulnerabilidade com o estabelecimento de dispositivos legais que venham ao seu amparo.

O consumidor é vulnerável, não há dúvida. Em uma sociedade hipermoderna ${ }^{2}$, dominada por meios de comunicação cada vez mais efetivos, instantâneos, a tecnologia evolui com grande rapidez em curto espaço de tempo, sendo difícil acompanhar suas inovações, o que tem levado ao surgimento de distúrbios de saúde específicos e próprios desse período, a

O existencialismo é uma corrente de pensamento que propõe analisar o homem em sua relação com o mundo, distanciando-se das propostas filosóficas que idealizam a condição humana. Jean Paul Sartre $(1905$ - 1980) é o principal expoente desta escola e defendia que a existência precede a essência.

2 O termo sociedade hipermoderna é proposta pelo filósofo francês Gilles Lipovetsky (1944) na obra Os tempos hipermodernos, na qual o autor defende que ocorreu uma transição da pós-modernidade para o que denomina hipermodernidade.

SCIENTIAIURIS,Londrina, v.18,n.1,p.135-152,jul.2014 | DOI: 10.5433/2178-8189.2014v18n1p135 
exemplo da síndrome da dependência tecnológica ${ }^{3}$. Nesse sentido, a posição do consumidor é cada vez mais ameaçada, pois pouco conhecendo o produto que consome, o serviço que utiliza, e, menos ainda, a lógica envolvida nas relações de consumo, figura na maioria das vezes como um mero aderente da vontade do fabricante e dos fornecedores, que oferecem e ditam as opções de consumo disponíveis. Surge, daí, um elemento a mais para reforçar a sua vulnerabilidade: o neuromarketing.

O neuromarketing é um tema que tem relação direta com o princípio da vulnerabilidade, pois importa em um conjunto de conhecimentos que analisam fisiologicamente o cérebro do consumidor, bem como as manifestações corporais no momento do ato de consumo, no afã de propor novas estratégias de marketing e de comportamento consumerista. Assim, como equilibrar a relação estabelecida entre o consumidor e o fornecedor, a qual é notoriamente assimétrica, quando o último se encontra munido de uma série de instrumentos e estudos científicos que perscrutam e procuram imputar o querer do primeiro? O consumidor passa a tomar decisões que não são decorrência de uma vontade refletida, mas antes condicionadas, programadas e neurologicamente estudadas.

As normas brasileiras estabelecem sérias restrições à publicidade de determinados produtos (bebidas alcoólicas, fumo, medicamentos e agrotóxicos), pois entendeu o legislador que a vontade do consumidor deve ser resguardada, reconhecendo também a sua vulnerabilidade. Técnicas de neuromarketing já são visíveis no mercado de consumo brasileiro, aonde várias empresas vêm realizando vultosos investimentos na qualificação de profissionais e em pesquisas nesta área do conhecimento.

É nesse entorno de discussão que se situa este artigo, o qual tem por proposta refletir sobre o impacto das técnicas de neuromarketing no aprofundamento da vulnerabilidade do consumidor, pois se parte do princípio que a legislação brasileira não se encontra ainda dotada de dispositivos aptos a proteger a vontade refletida do consumidor. Defende-se, ao final, que sejam introduzidos no Código de Defesa do Consumidor ou em legislação apartada dispositivos sobre a matéria, sob pena da repercussão negativa na utilização indiscriminada dessas técnicas na vulnerabilidade e na própria intimidade do consumidor.

\footnotetext{
3 A Síndrome da Dependência Tecnológica, também conhecida como tecnose, é uma doença psiquiátrica que decorre da utilização excessiva de recursos tecnológicos e da internet. Esta enfermidade tem bastante semelhança com as dependências químicas de drogas e álcool, inclusive seu tratamento é bem similar.
}

SCIENTIAIURIS, Londrina, v.18,n.1,p.135-152,jul.2014 | DOI: 10.5433/2178-8189.2014v18n1p135 


\section{A SOCIEDADE DE CONSUMO}

O ponto de partida para se compreender a atual sociedade de consumo é a Revolução Industrial ocorrida na Inglaterra, em meados do século XVIII, e que, no século XIX, se expandiu pelo mundo. Aquele conjunto de mudanças tecnológicas importou em profundas alterações na sociedade da época, inaugurando um novo modelo capitalista (capitalismo industrial) caracterizado por uma divisão do trabalho até então inexistente, invenções que permitiram maximizar a produção, a superação do trabalho humano pela máquina e o estabelecimento de uma nova relação capital x trabalho.

O liberalismo ${ }^{4}$ é a teoria política e econômica que justifica esse período, o qual propunha uma ampla liberdade individual, a defesa da propriedade privada, o livre mercado, o estado de direito e, sobretudo, a não ingerência estatal, cabendo ao Estado apenas assegurar as condições mínimas de desenvolvimento social e proteção da propriedade. É neste contexto político e econômico que nasce a sociedade de consumo, inicialmente tímida, pois as práticas comerciais até aquele momento tinham por objetivo apenas saciar as necessidades existentes, preencher as carências surgidas com o aumento gradativo da complexidade social, diferentemente do que ocorre hoje, quando é a própria sociedade de consumo que gera as necessidades, incitando um consumo desregrado e desnecessário.

Cabe assinalar, contudo, que a forma como hoje é conhecida e vivenciada a sociedade de consumo tem relação direta com o fim da Grande Guerra e com os desdobramentos dos acontecimentos ocorridos após o seu término. Vários institutos e ramos do conhecimento surgem e se desenvolvem nesse momento, importando em contribuições significativas ao atual modelo consumerista. Um exemplo foram as contribuições das técnicas de propaganda nazista da $2^{\mathrm{a}}$ guerra mundial para o desenvolvimento da publicidade comercial.

Lipovetsky (2007, p. 26) apresenta um quadro esquemático de todo este percurso histórico pelo qual transitou a sociedade de consumo, investigando a relação consumo e capitalismo, propondo uma divisão, em três momentos, do que denomina capitalismo de consumo, ao afirmar que,

${ }^{4}$ O liberalismo é um sistema político-econômico baseado na defesa da liberdade individual que abrange o campo econômico, político e religioso contra as ingerências e atitudes do Estado. O Liberalismo: antigo e moderno, de autoria de José Guilherme Merquior, é um dos mais brilhantes ensaios escritos sobre o tema.

SCIENTIAIURIS, Londrina, v.18,n.1,p.135-152,jul.2014 | DOI: 10.5433/2178-8189.2014v18n1p135 
se a hipótese de uma nova etapa histórica da civilização consumidora é justa, é possível propor um esquema de sua evolução fundado na distinção de três grandes momentos. Não é necessário esclarecer que a "descrição" que dou deles é das mais sumárias, sendo o objetivo procurado apenas o de abarcar num único olhar um fenômeno complexo e secular, pôr em perspectiva o sentido das mudanças em curso, inscrevendo o presente na história longa da civilização de massa.

A primeira fase se inicia nos anos 1880 , perdurando até a segunda guerra mundial. O que marca este período é a produção em larga escala e uma nova filosofia comercial, na qual o lucro provinha da venda de uma maior quantidade de produtos a uma pequena margem de lucro, preferentemente, a vendas de pequenas quantidades com margens expressivas. É o momento também do desenvolvimento do marketing de massa, pois "até os anos 1880, os produtos eram anônimos, vendidos a granel, e as marcas nacionais, muito pouco numerosas" (LIPOVETSKY, 2007, p.29).

Como decorrência desse marketing de massa, as empresas passam a empacotar e rotular seus produtos, padronizando-os, atribuindo nomes, prática até então incomum, e investindo pesadas somas em publicidade para torná-los conhecidos da população. É o período do surgimento das marcas célebres. Muitas destas chegaram até os dias de hoje, a exemplo da Coca-Cola, fundada em 1886, no estado da Geórgia, nos Estados Unidos, e que originalmente foi concebida para ser um remédio, mas hoje é o refrigerante mais popular e consumido no mundo.

É nesse primeiro momento, portanto, que surge o consumo de marcas, no qual o que fideliza o consumidor é o produto e não a relação que, outrora, era mantida com o vendedor. Surgem também as grandes lojas de departamentos, isto é, grandes magazines a exemplo da Printemps, em 1865, e Le Bon Marché, em 1869, ambas na França. O consumo é percebido nessa fase como projeção social, onde o produto consumido é símbolo de notoriedade, de destaque, pois ainda muito restrito a um grupo pequeno de pessoas.

O segundo momento se inicia por volta de 1950, em um momento histórico de excepcional crescimento econômico, pelo aumento da produtividade no trabalho e pela contribuição do fordismo à regulação da economia, identificando essa fase como de uma sociedade da abundância, quando o poder de compra é quadruplicado para deleite do consumo de massa, embalando os sonhos dos consumidores (LIPOVETSKY, 2007).

SCIENTIAIURIS, Londrina, v.18,n.1,p.135-152,jul.2014 | DOI: 10.5433/2178-8189.2014v18n1p135 
A principal característica desse novo ciclo econômico é a ampliação das novas estratégias de marketing, as quais passam a atuar de forma segmentada, atingindo públicos direcionados, em que o consumidor passa a ser visto não de forma geral, mas integrante de um dado grupo, quer por fatores socioculturais, econômicos, estéticos e outros. $\mathrm{O}$ consumo, então, passa a ser a expressão de um modo de vida, fundamento do bem estar, da felicidade, e não é mais tão somente projeção social, mas, sobretudo, dirigido para o íntimo, para a satisfação do desejo e do prazer, podendo-se afirmar que esta sociedade do desejo se apresenta "impregnada de imaginário de felicidade consumidora, de sonhos de praia, de ludismo erótico, de modas ostensivamente jovens" (LIPOVETSKY,2007, p. 35).

A partir do final dos anos 70, ingressa-se na terceira fase, o qual tem por peculiaridades um forte individualismo e um estímulo desenfreado ao consumo, o passa a ser movido por impulso, sem uma razão explicativa, de forma inconsciente e predatória, modelo de denominado de sociedade do hiperconsumo. É este o paradigma atual, em que o ato de consumir deixou de ser a forma de satisfazer uma necessidade para se tornar, sobretudo, um ato realizado compulsoriamente, de forma irrefletida e mecânica, onde o consumidor é induzido a se comportar de determinada maneira e reduzido em sua vontade livre.

\section{OS PRINCÍPIOS DA VULNERABILIDADE E DA INFORMAÇÃO: SITUANDO O CONSUMIDOR NA SOCIEDADE DE HIPERCONSUMO}

O direito das relações de consumo surgiu como o escopo de equilibrar a relação travada entre fornecedores e consumidores, notadamente, em uma época em que, cada vez mais, o consumidor menos domina e compreende o processo de produção e distribuição dos bens na sociedade. O fornecedor é o elo forte, pois domina os meios de produção, conhecendo pormenorizadamente a cadeia produtiva e com amplo acesso a todas as informações que envolvem o produto e as técnicas de criação de desejo.

Ao mesmo tempo o consumidor se vê perdido, náufrago em um mar de informações truncadas, desconexas, descontínuas e ao mesmo tempo rápidas, coloridas e glamorosas, para as quais não possui capacidade de decodificação e de posicionamento. É o vulnerável, a parte fraca que depende do fornecedor para suprir suas necessidades, nem sempre reais, estando submisso frente às opções que disponibilizadas por este no mercado consumidor. Conforme Efing (2004, p. 105),

SCIENTIAIURIS, Londrina, v.18, n.1, p.135-152,jul.2014 | DOI: 10.5433/2178-8189.2014v18n1p135 
fica claro, portanto, com base nesta assertiva, que a situação do consumidor é a de submissão ao poder dos fornecedores, uma vez que sua escolha de bens de consumo não poderá exceder aquilo que é oferecido no mercado. Esta submissão é a responsável pela fundamentação do princípio da vulnerabilidade que, partindo do pressuposto de que o consumidor depende dos empresários, fornecedores pessoas físicas ou entes despersonalizados para a manifestação de sua vontade, conclui ser o consumidor imprescindivelmente a parte mais fraca da relação de consumo.

No atual paradigma da sociedade de consumo, vicejam os contratos de adesão aos quais, muitas vezes, não permitem ao consumidor nem saber com quem contrata; onde vários serviços essenciais são prestados no regime de monopólio, a exemplo do fornecimento de luz, água, telefonia fixa e vários serviços públicos ou sob concessão; em que as compras e ofertas de serviços pela internet vêm crescendo em ritmo desenfreado sem qualquer tipo controle pelo consumidor; na qual bancos e financeiras oferecem crédito fácil e abundante. Destarte fica a pergunta: qual a liberdade de escolha do consumidor e de que forma entende ele sua vulnerabilidade?

Vulnerabilidade e informação são dois princípios básicos quando se tratam das relações consumeristas, os quais são tratados no bojo da Política Nacional das Relações de Consumo, prevista no art. $4^{\circ}$ do Código de defesa do Consumidor, sendo certo afirmar, como o faz Filomeno (2007, p. 11), que

com efeito, o art. $4^{\circ}$ do Código de Defesa do Consumidor constitui-se numa verdadeira alma, no sentido de que visa a atender não apenas às necessidades dos consumidores e respeito à sua dignidade - de sua saúde e segurança, proteção de seus interesses econômicos, melhoria de sua qualidade de vida, como também à imprescindível harmonia das relações de consumo.

O princípio da vulnerabilidade ${ }^{5}$ é um elemento chave para se compreender a posição do consumidor no mercado de consumo, pois significa que este é o

\footnotetext{
5 José Geraldo Brito Filomeno realiza interessante ponderação sobre a vulnerabilidade do consumidor, como a seguir: "por vulnerabilidade, há de se entender a fragilidade dos consumidores, em face dos fornecedores, quer no que diz respeito ao aspecto econômico e de poder aquisitivo, quer no que diz respeito às chamadas informações disponibilizadas pelo próprio fornecedor ou ainda técnica. Ora, referidas informações, que podem ser, por exemplo, verdadeiras ou falsas, ou então desatenderem às expectativas dos consumidores, mediante oferta, publicidade ou apresentação (embalagens, bulas de remédios, manuais de uso, cartazes e outros meios visuais), apresentando-se, por conseguinte, na fase chamada pré-contratual. Essa vulnerabilidade ainda está presente na fase de contratação na aquisição de um produto ou da prestação de um serviço. Sabendo-se que hoje em dia dada a massificação da produção e, consequentemente, do crédito e das vendas, a grande maioria dos contratos é de
} 
mais débil, a parte mais frágil, o alvo para o qual são direcionados todos os mecanismos de convencimento e de manipulação postos à disposição do fornecedor no intuito de vender e impor os seus produtos e serviços. A vulnerabilidade é um conceito de direito material ${ }^{6}$, sendo uma qualidade intrínseca, imanente a todos que se encontram na posição de consumidor, não importando sua condição social, cultural ou econômica, logo, a imediata aplicação do CDC é forma de minorar esta desigualdade existente.

O direito à informação é também princípio imprescindível quando se busca delimitar o espaço ocupado pelo consumidor na sociedade de consumo, pois informação clara, precisa, honesta permite ao consumidor decidir de forma refletida sobre a necessidade, ou não, de determinado produto ou serviço, sendo expressão da liberdade do ato de consumir. Ocorre que, muitas vezes, o direito à informação não é observado, prejudicando o consumidor em suas decisões diárias e o colocando em posição desfavorável perante o fornecedor.

Um exemplo que bem ilustra esta discussão é a atinente a rotulagem de produtos que contenham matéria prima transgênica no Brasil e o direito à informação do consumidor, tema que vem encontrando ferrenha oposição das empresas. No Brasil, em que pese toda a polêmica que envolve o assunto ${ }^{7}$, bem como a discussão jurisprudencial e doutrinária, alguns estados da Federação, a exemplo de São Paulo ${ }^{8}$, resolveram editar leis, determinando a rotulação dos produtos de natureza transgênica em seu território, com o objetivo de garantir o direito à informação do consumidor e o exercício do seu direito de escolha.

adesão, ou seja, contrato em que as condições gerais e cláusulas são unilaterais e previamente ditadas por apenas uma das partes, cabendo à outra tão-somente aceitá-las ou não, é grande o risco de prejuízo ao consumidor, parte mais fraca. E por último esta vulnerabilidade se manifesta na fase pós-contratual, em que podem surgir vícios ou defeitos, tornando os produtos adquiridos ou serviços contratados inadequados aos fins aos quais se destinam, ou então nocivos ou perigosos à incolumidade física ou saúde dos consumidores que, além disso, poderão experimentar prejuízos em decorrência destes mesmos vícios os defeitos".

${ }^{6}$ É importante destacar que existe diferença entre vulnerabilidade e hipossuficiência. O primeiro é conceito de direito material e tem cunho geral, enquanto a hipossuficiência equivale a um conceito processual e deve ser tomada de forma particularizada.

7 Desde o Decreto ${ }^{\circ} 4.680$, de 24 de abril de 2003, que regulamentava o direito à informação ao consumidor, quanto aos alimentos e ingredientes alimentares destinados ao consumo humano ou animal que contenham ou sejam produzidos a partir de organismos geneticamente modificados, através de rótulo com símbolo próprio, definido pela Portaria . $^{\circ}$ 2658, de 22 de dezembro de 2003, do Ministro de Estado da Justiça, cujos efeitos práticos até hoje ainda não foram notados pela população. Sobre o tema ver MENDONÇA, Gilson Martins, COELHO, Sérgio Reis. A ética da informação e o direito de escolha na questão da rotulagem dos transgênicos. Disponível em $<\mathrm{http}$ :/ /www.conpedi.org.br/manaus/arquivos/anais/salvador/gilson_martins_mendonca.pdf $>$ Acesso em 23 out. 2012 .

8 Vide Lei estadual $\mathrm{n}^{\mathrm{o}} 14.274$, de 16 de dezembro de 2010, que dispõe sobre a rotulagem de produtos transgênicos no Estado e dá outras providências.

SCIENTIAIURIS, Londrina, v.18,n.1,p.135-152,jul.2014 | DOI: 10.5433/2178-8189.2014v18n1p135 


\section{AS PRÁTICAS COMERCIAIS NO CDC: DISCUTINDO O PAPEL DO MARKETING}

Percebida a posição ocupada pelo consumidor na relação de consumo, a qual, sem qualquer margem de erro, é inferior a ocupada pelo fornecedor, é o momento de se discutir a contribuição do marketing para esse estado de coisas.

O Código de Defesa do Consumidor cumpre no Brasil o objetivo de estabelecer regras claras de convivência na sociedade de consumo, ressaltando Benjamin (2007, p. 251) que esta regulamentação não ocorre "com o intuito de reprimi-la, mas apenas de colocá-la a serviço do interesse público". Dentre as várias regras trazidas pelo $\mathrm{CDC}$, destacam-se as atinentes as práticas comerciais e, nestas, as referentes ao marketing e a publicidade, temas para os quais o código consumerista dedicou uma atenção especial. Deve-se atentar ao fato de que marketing e publicidade não são sinônimos, mas coexistem em uma relação de gênero e espécie. O marketing ${ }^{9}$ engloba além da publicidade, que é seu aspecto mais importante, outras formas de expressão, a exemplo das vendas por correspondência, vendas a prestação, as amostras gratuitas, descontos, concursos, etc.

A necessidade de estabelecer uma regulamentação para o Marketing decorre do fato, conforme Solomon (2002, p. 28), de se viver em um mundo

\footnotetext{
Raimar Richers faz uma rápida abordagem sobre a evolução do Marketing: "apesar de sua juventude, o Marketing já passou por uma série de fases conotativas bem distintas e em parte até divergentes. Houve épocas em que as definições se concentravam nos aspectos primordialmente legais, relacionados à transferência de posse quando da compra e venda de bens. Em outras ocasiões, a ênfase fora dada a aspectos relacionados à distribuição, sobretudo quando, nos EUA, surgiram conflitos entre os interesses de poderosos grupos de produtores e distribuidores de bens. Durante muito tempo prevaleceu como definição mais divulgada a da Associação Americana de Marketing (AMA), que caracterizava esta área como abrangendo todas as atividades que envolvem o fluxo de bens e serviços entre o produtor e o consumidor. Mas essa definição não resistiu às críticas de inúmeros representantes, não só do mercado acadêmico, como também dos praticantes de Marketing. Ela deu lugar a uma interpretação mais ampla e mais voltada a dois aspectos primordiais: à responsabilidade das funções administrativas dentro do processo de Marketing na empresa (o chamado Managerial Marketing) e à abordagem sistêmica que se preocupa com a integração ordenada entre os diversos instrumentos que participam de um processo mercadológico qualquer. A mais recente das modificações conceituais do Marketing surgiu em consequência das repercussões dos movimentos consumeristas mundiais, de um lado, e, do outro lado, do reconhecimento de que o conceito de Marketing poderia ter aplicação e utilidade em áreas não necessariamente restritas à atuação das empresas privadas. Sob essas influências, o conceito ampliou-se para abranger áreas de ordem macro (como algumas das funções de um Estado moderno ou de uma comunidade social), bem como as atividades de organizações que não necessariamente visassem lucros nas suas transações, tais como igrejas, hospitais ou partidos políticos. Desde então, o Marketing ampliou os seus horizontes para além das empresas particulares, e tornou-se uma atividade-irmã de funções sociais, como a prática e o planejamento urbano".
}

SCIENTIAIURIS, Londrina, v.18, n.1,p.135-152,jul.2014 | DOI: 10.5433/2178-8189.2014v18n1p135 
"significativamente influenciado pelas ações dos profissionais de marketing", no qual todos se encontram "rodeados de estímulos de marketing na forma de comerciais, lojas e produtos competindo pela nossa atenção e nosso dinheiro". Essa inserção do marketing na vida social, no cotidiano, faz com que a própria percepção dos fatos que acontecem na sociedade seja, em muitos casos, decorrência de uma filtragem realizada pelos profissionais do marketing, que acabam por estabelecer padrões de conduta e de compreensão social, no intuito de melhor vender seus produtos. Segundo Solomon (2002, p. 28), "confiamos neles para nos vender produtos que são seguros e têm o desempenho prometido, para nos dizer a verdade sobre o que estão vendendo e garantir preço e distribuição justos para esses produtos".

$\mathrm{O}$ marketing é regulado pelo $\mathrm{CDC}$, pois este como o instrumento, por excelência, de regulação das relações de consumo no Brasil traz, em seu bojo, um conjunto de dispositivos tratando deste tema durante as fases em que se desenvolve a relação consumerista. Para Benjamin (2007, p. 261), o CDC enxerga o marketing sob três ângulos:

Primeiramente, sob o aspecto pré-contratual, o marketing, preenchidos certos requisitos, é conferido efeito vinculante. Além disso, o marketing projeta-se na própria estrutura interior do contrato, sobrepondo-se às cláusulas que se proponham a negar, diretamente ou indiretamente, sua força vinculante. Finalmente o marketing,em momento pós-contratual ou metacontratual, acarreta o direito de indenizar, na hipótese de dano ao consumidor.

O tratamento amplo do marketing no CDC busca compatibilizá-lo com a defesa do consumidor, pois estes fenômenos, que não são incompatíveis, devem conviver em harmonia, pois buscam o mesmo objetivo que é a satisfação das necessidades do consumidor. Um dos grandes problemas que se verifica nesta relação direito e marketing, todavia, intensa e com muitos pontos em comum, é quanto à forma como se desenvolve o direito e o marketing. O direito é lento por natureza, meticuloso, formal, possuindo um ritmo de transformação vagaroso, enquanto o marketing é dinâmico, célere, o que torna problemático adotar leis rígidas de controle deste último ${ }^{10}$.

Em virtude deste fato, o CDC adotou dispositivos que tratam o marketing de forma genérica, permitindo que a jurisprudência, de forma criativa e inovadora,

\footnotetext{
${ }^{10} \mathrm{O}$ que se pode apontar nesse sentido é a atuação do Conselho Nacional de Autorregulamentação Publicitária - CONAR, que surge no final da década de 70 justamente para se contrapor à iniciativa governamental de regular o setor. Vide <http://www.conar.org.br/>.
}

SCIENTIAIURIS, Londrina, v.18,n.1,p.135-152,jul.2014 | DOI: 10.5433/2178-8189.2014v18n1p135 
enfrente as diversas situações que se apresentam na relação travada entre o marketing e os direitos dos consumidores. Essa relação entre o direito e o marketing é bem explicitada por Benjamin (2007, p. 262), para quem

a função do direito ao controlar o marketing é, portanto, a de estabelecer parâmetros mínimos de conduta, respeitando sempre - como o quer a Constituição Federal - a livre iniciativa. É por este prisma que se deve buscar a compatibilização entre 'a defesa do consumidor' e a 'a liberdade de marketing'. Seria tal objetivo um simples ideal? Acreditamos que não. Marketing e defesa do consumidor funcionam no mercado e são, portanto, dele dependentes. Sem mercado e concorrência não há como se falar em marketing e proteção do consumidor. Logo, ao se proteger o mercado, ao se assegurar o seu funcionamento adequado, especialmente pelas normas de defesa do consumidor, em verdade, se está garantindo a própria sobrevivência do marketing.

$\mathrm{O}$ que o CDC pretende, ao estabelecer toda uma regulamentação do marketing, é que este seja exercido de forma a respeitar o consumidor e seus direitos, se apresentando de forma clara, precisa, em que os valores reinantes em uma relação de consumo, tais como informação de qualidade, confiança, respeito, sejam resguardados e protegidos, bem como seja expurgado o mau uso das técnicas de marketing que visem à exploração, à fraude e ao prejuízo dos consumidores.

\section{O NEUROMARKETING: UM NOVO MOMENTO NA CIÊNCIA DO MARKETING}

O estudo do comportamento do consumidor é de fundamental importância para os profissionais do marketing, pois se trata de área do conhecimento caracterizada por uma profunda interdisciplinaridade. $\mathrm{O}$ estudo deste tema significa amealhar conhecimentos oriundos de diversos ramos do saber, tai como, a psicologia, a economia, a história, a antropologia, dentre outras, no afã de compreender como ocorre o processo decisório no ato da compra.

Para Solomon (2007, p. 24) o comportamento do consumidor é "o estudo dos processos envolvidos quando os indivíduos ou grupos selecionam, compram, usam ou dispõem de produtos, serviços, ideias ou experiências para satisfazer necessidades e desejos". Entretanto, várias são as abordagens teóricas sobre o comportamento do consumidor, as quais adotam as mais diversas perspectivas 
visando explicar o processo decisório de compra. Pinheiro et al. (2006), por exemplo, apontam em sua obra algumas das mais importantes teorias empregadas para se compreender o comportamento do consumidor.

Desde uma perspectiva histórica, esses autores apontam uma teoria da racionalidade econômica, a qual propõe que o comportamento do consumidor obedece a uma lógica do maior benefício ao menor custo possível. Para esta teoria, o comportamento do consumidor "tem por horizonte a maximização da utilidade, isto é, os esforços de escolha de um consumidor sempre teriam por horizonte a maximização dos graus de satisfação psicológica e prazer obtidos com o uso dos produtos e serviços obtidos" (PINHEIRO et al., 2006, p. 15).

Com base na psicologia, apresentam os autores outras três importantes teorias comportamentais do consumo, as quais enfatizam a necessidade de, primeiro, melhor compreender o que acontece na mente do consumidor para, então, desvendar os motivos de seu comportamento. A primeira é denominada teoria comportamental do consumo, que busca estabelecer relações entre o comportamento do consumidor e o meio ambiente em que este vive. Nela, "o consumo, um tipo de comportamento, é um conjunto de reações fisiológicas e comportamentais observáveis, geradas por estímulos localizados no meio ambiente" (PINHEIRO et al., 2006, p. 16). Logo, é com base no estudo dos estímulos presentes no meio ambiente que se pode compreender a forma de comportamento do consumidor, ou seja, a sua aproximação (reação positiva) ou afastamento (reação negativa) das opções de consumo disponíveis no mercado consumidor.

A segunda é a teoria psicanalítica, criada por Sigmund Freud no final do século XIX e início do século XX, a qual propõe que o consumo é expressão de desejos inconscientes, pois o consumidor projeta nos produtos que compra todas as suas angústias, frustrações, conflitos e expectativas, funcionando o consumo como um modo de dar vazão a estes sentimentos que possui e estão represados. Conforme Pinheiro et al (2006, p. 18),

a teoria psicanalítica, desta forma, chama a atenção não apenas para os motivos inconscientes da compra, mas também para o seu caráter expressivo, posto que os consumidores projetam seus desejos nos produtos ofertados. A escolha dos produtos, então, dá-se de acordo com a capacidade de estes satisfazerem, mesmo que parcial e temporariamente, os impulsos inconscientes. Com base nesse raciocínio, cabe aos profissionais de marketing criar estratégias que ressaltem características dos produtos que despertem o desejo inconsciente dos consumidores.

SCIENTIAIURIS, Londrina, v.18,n.1,p.135-152,jul.2014 | DOI: 10.5433/2178-8189.2014v18n1p135 
A terceira e última é a teoria cognitivista do consumo, uma das mais utilizadas pelos pesquisadores hodiernamente, pois entende o comportamento do consumidor como oriundo da relação produto, consumidor e meio ambiente. Nessa perspectiva, o consumo é visto como um processo de tomada de decisão pelo qual o consumidor, diante de várias opções, pondera diversos fatores antes de decidir. Estes fatores são de ordem cognitiva tais como a percepção, aprendizagem, atitudes e valores; de ordem sociocultural, como a influência familiar; ou ainda de fatores oriundos do meio ambiente no momento da compra. É uma teoria integrativa, pois leva em consideração diversos aspectos para explicar o comportamento do consumidor.

Por fim, podem-se destacar as teorias sociais e antropológicas que são as que defendem o consumo como uma decorrência de processos sociais. Estas abordagens oferecem uma compreensão do consumo como inserido em uma dinâmica social e cultural própria, a qual possibilita que os indivíduos alcancem determinadas posições sociais. Examinadas todas estas teorias que objetivam compreender o comportamento do consumidor, percebe-se que a investigação nesta área do conhecimento é intensa, pois objetiva, sobretudo, fornecer subsídios aos profissionais do marketing para a sua atuação, tendo um caráter eminentemente prático.

É, neste contexto, que surge o neuromarketing, assunto relativamente novo, o qual teve início no final dos anos noventa em algumas universidades norte-americanas, destacando-se o Laboratório Mente do Mercado (Mind of the Market Laboratory) da Harvard Business School, onde um dos pesquisadores, Gerald Zaltman, médico, decidiu empregar aparelhos de ressonância magnética para fins de marketing. A expressão neuromarketing, no entanto, somente passa a ser utilizada no ano de 2002, quando foi cunhada por Ale Smidts, um professor de marketing na Erasmus University, em Roterdã, na Holanda.

O neuromarketing é uma nova disciplina ${ }^{11}$ que busca estudar quais são as variáveis capazes de influenciar o comportamento do consumidor no processo

${ }^{11}$ A Revista Planeta, na edição de julho de 2010, trouxe uma interessante reportagem sobre o neuromarketing. Da citada reportagem extrai-se o seguinte trecho: "Auxiliados por equipamentos de ressonância magnética, os neurocientistas conseguem registrar instantaneamente as atividades cerebrais e a formação de sinapses e reações, monitorando as emoções que sentimos durante as compras. Enquanto somos expostos a mensagens relacionadas com experiências de consumo, essas sofisticadas técnicas de imageamento identificam na tela do computador, por meio de gráficos coloridos e em terceira dimensão, as zonas do cérebro estimuladas e o funcionamento de cada pedaço de nossa mente.

Já com a tomografia de ressonância magnética funcional, os cientistas produzem imagens coloridas da troca de substâncias no cérebro e registram instantâneos da localização e intensidade da atividade

SCIENTIAIURIS, Londrina, v.18,n.1,p.135-152,jul.2014 | DOI: 10.5433/2178-8189.2014v18n1p135 
decisório de compra, utilizando para este fim ferramentas da psicologia e da medicina. Como afirma Soares Neto (2007, p. 10), em dissertação que cuida do neuromarketing,

os avanços na ciência do cérebro vêm permitindo desenvolvimentos inovadores voltados para o conhecimento de experiências inconscientes dos consumidores. Tais novidades relacionam-se à técnicas de neuroimagem, como a imagem por ressonância magnética funcional (functional magnetic resonance imaging - FMRI), a tomografia ótica funcional difusa (FDOT) (ZALTMAN, 2003) e a tomografia por emissão de pósitrons (Posidron Emission Tomography - PET) (KENNNING, P. ; PLASSMANN, H., 2005). Essas técnicas de escaneamento do cérebro produzem figuras da estrutura ou do funcionamento dos neurônios (KOSSLYN; ROSENBERG, 2001). Por meio da neuroimagem, os pesquisadores são capazes de observar diretamente as atividades cerebrais, enquanto os indivíduos se envolvem em várias tarefas mentais, ou seja, registram-se imagens do cérebro dos consumidores e identificam-se quais áreas da mente são ativadas quando as pessoas são expostas a marcas, imagens, vídeos, produtos ou propagandas comerciais.

Em que pese o neuromarketing ser recente, estando ainda em seus primeiros passos, a verdade é que várias empresas multinacionais importantes estão investindo somas expressivas em pesquisas nesta área, a exemplo, da General Motors, Ford, Daimler, GE, Coca-Cola, McDonald's, K-Mart, Kodak, Levi-Strauss e Delta Airlines.

Uma técnica de neuromarketing que já é bastante comum é o branding sensorial $^{12}$, no qual os sentidos são seduzidos por aromas, por estímulos

cerebral. Sinais de radiofrequência fornecem a imagem das alterações no fluxo sanguíneo e na oxigenação em determinadas áreas cerebrais. O processo também mostra como a intensidade cerebral se altera diante de anúncios publicitários.

É assim, por meio da atividade elétrica cerebral, que os neurocientistas esperam explicar o que move a decisão das compras e obter dados e informações relevantes sobre os processos e as variáveis mentais que possam explicar melhor as expectativas, preferências, motivações e comportamentos relacionados com o consumo, ajustando as estratégias de marketing das empresas.

Entretanto, os neuropsicólogos asseguram que não existe um botão para o consumo porque a tomada de decisões envolve diversas regiões do cérebro que atuam de forma sequencial num curto espaço de tempo. Por isso, segundo eles, a atividade prática do neuromarketing até agora se limita à fotografia do cérebro no instante exato da tomada de decisão. O grande avanço científico é conseguir ver na prática como as funções cerebrais (emoção, memória e raciocínio) são ativadas diante de um estímulo. Disponível em <http://www.terra.com.br/revistaplaneta/edicoes/453/ artigo 178293-5.htm>. Acesso em 10.07.2011.

${ }^{12}$ A Revista Planeta menciona um caso conhecido de branding sensorial no Brasil, segundo o periódico: "Em 2001, uma ação de branding sensorial usada pela Bauducco foi bastante comentada pelas pessoas e talvez você até se lembre (ou tenha participado) dela: no Natal daquele ano, a empresa espalhou o aroma de panetone em 32 salas de cinema de São Paulo, enquanto imagens do produto 
auditivos, visuais que forçam os consumidores a comprar, atuando sobre a própria fisiologia, tornando o ato de compra não uma ação refletida, mas imposição exigida pelo organismo levado à desejar a experiência de consumo do produto e o consequente sentimento de satisfação. Esse estado da arte permite perceber o neuromarketing como ponto central de uma discussão sobre questões éticas, as quais não são tratadas no marketing tradicional, pois que este trabalha, principalmente, com pesquisas qualitativas, enquetes, entrevistas, sempre atuando externamente ao indivíduo, buscando compreender o comportamento do consumidor a partir de elementos externos a este.

Ainda que essa forma de trabalhar do marketing tradicional gera alguns problemas, pois como afirma Soares Neto (2007, p. 13),

é nesse ponto que Lima (2005) chama a atenção do problema de desenvolver campanhas publicitárias fundamentadas em dados colhidos através de entrevistas não totalmente confiáveis. Segundo esse autor, dois motivos podem gerar dados equivocados, o primeiro é que os questionários não conseguem articular questões-chave de maneira adequada e nada garante que o entrevistado esteja falando a verdade, e o segundo é que as pessoas expressam-se mal e entediam-se facilmente,

todavia, o que o marketing tradicional objetiva é vender produtos, e as ações que emprega não atuam na fisiologia do consumidor, mas apenas no plano psicológico, o que fez o CDC estabelecer regras bastante claras e rígidas quanto à publicidade.

Por outro lado, o neuromarketing trabalha na lógica inversa, pois visa o estudo do comportamento do consumidor tendo por referência elementos internos, fisiológicos, investigando os processos químicos e cerebrais que ocorrem na mente do consumidor para, a partir desses dados, sugerir intervenções e novas formas de abordagem comercial, retirando ao máximo do indivíduo consumidor sua capacidade volitiva.

Ante esse panorama, percebe-se que com as técnicas de neuromarketing surgem questões éticas que não existiam antes no marketing tradicional, e por isso ainda não reguladas, as quais não podem ser afastadas e necessitam ser objeto de um rigoroso debate. Afinal como compreender o ato de compra depois do neuromarketing? A compra é decorrente de uma vontade refletida do

eram exibidas na tela, antes de o filme começar. Nem é preciso contar como foram as suas vendas de panetones naquele ano. Disponível em <http://www.terra.com.br/revistaplaneta/edicoes/453/ artigo178293-5.htm>. Acesso em 10.07.2011.

SCIENTIAIURIS, Londrina, v.18,n.1,p.135-152,jul.2014 | DOI: 10.5433/2178-8189.2014v18n1p135 
consumidor, tendo em vista uma necessidade ou este atua como uma espécie de zumbi, executando um programa acionado em sua mente?

Não há dúvida que o neuromarketing veio aprofundar a vulnerabilidade do consumidor, pois abriu um novo campo de investigação, bastante promissor, onde se permitiu ao profissional do marketing ter acesso às reações físicas do consumidor, podendo então melhor conduzir as suas campanhas e intervenções publicitárias. Em virtude de toda essa discussão que envolve o neuromarketing, há a necessidade de se estabelecer no CDC dispositivos que tratem diretamente do tema, pois a lei apenas cuida das práticas comerciais envolvendo o marketing tradicional. Em outras palavras, não há como fechar os olhos a essa realidade sob pena de se aprofundar cada vez mais a vulnerabilidade do consumidor.

\section{CONSIDERAÇÕES FINAIS}

Por ser ainda um debate novo, o neuromarketing ainda não foi devidamente percebido pelo direito, o que não acontece na publicidade e na administração, áreas do conhecimento que vêm investigando profundamente o tema. $\mathrm{O}$ neuromarketing abre muitas possibilidades para que se influa no comportamento do consumidor, tornando necessária uma discussão ampla em suas bases e nas técnicas que propõe, enfim, tudo que o envolve, pois as conquistas desse método podem repercutir muito negativamente na relação consumidor-fornecedor.

Como já dito, o consumidor é o vulnerável, o elo fraco da relação de consumo, logo a exigência do direito protegê-lo ante as investidas do fornecedor. Ocorre que o neuromarketing reforça essa vulnerabilidade, pois disponibiliza um conjunto de técnicas já desenvolvidas e a desenvolver que verticalizam ainda mais a relação de consumo, bem como afetam a intimidade do consumidor ao analisá-lo de forma interna, e não externamente, como faz o marketing tradicional.

Frente a essa realidade, não pode o direito quedar inerte, mas deve tutelála buscando compreender as propostas do neuromarketing e as técnicas já existentes, no intuito de fazer inserir no Código de Defesa do Consumidor dispositivos tratando do tema à semelhança do que foi realizado com o marketing e a publicidade. Esta modificação legislativa, por fim, é importante, pois repercutirá na minoração do consumo irrefletido, decorrente de abordagens publicitárias aéticas que utilizam de forma irresponsável e desmedida, as técnicas do neuromarketing e estabelecerá um padrão normativo a ser observado por todos aqueles que atuam no segmento publicitário e de vendas. 


\section{REFERÊNCIAS}

BENJAMIN, Antônio H. de V. e. Das Práticas Comerciais. In: Código Brasileiro de Defesa do Consumidor: comentado pelos autores do anteprojeto. Rio de Janeiro: Forense, 2007.

EFING, Antônio Carlos. Fundamentos do direito das relações de consumo. 2 ed. Curitiba: Juruá, 2004.

FILOMENO, José Geraldo Brito. Manual de direitos do consumidor: doutrina, jurisprudência e aspectos práticos. 9. ed. São Paulo: Atlas, 2007.

LIPOVETSKY, Gilles. A felicidade paradoxal: ensaio sobre a sociedade de hiperconsumo. São Paulo: Companhia da letras, 2007.

MENDONÇA, Gilson Martins, COELHO, Sérgio Reis. A ética da informação e o direito de escolha na questão da rotulagem dos transgênicos. Disponível em <http:/www.conpedi.org.br/manaus/arquivos/ anais/salvador/gilson_martins_mendonca.pdf $>$ Acesso em 23 out. 2012.

PENDERGRAST, Mark. Por Deus, pela pátria e pela Coca-Cola. Rio de Janeiro: Ediouro, 1993.

PINHEIRO, Roberto Meireles; CASTRO, Guilherme Caldas e outros. Comportamento do consumidor e pesquisa de mercado. Rio de Janeiro: Editora FGV, 2006.

RICHERS, Raimar. Marketing: uma visão brasileira. São Paulo: Negócio, 2000.

. O que é Marketing. 15. ed. São Paulo: Brasiliense, 1994.

SOARES NETO, João Batista. Mapeando fundamentos do constructo neuromarketing com profissionais de empresas de publicidade. Dissertação de Mestrado. Natal: UFRN, 2007. 
SOLOMON, Michael R. O comportamento do consumidor: comprando, possuindo e sendo. Porto Alegre, Bookman, 2002.

ZALTMAN, Gerald. Afinal, o que os clientes querem. Rio de Janeiro: Campus, 2003.

Artigo recebido em: 27/03/2014 Aprovado para publicação em: 09/07/2014

Como citar: MENDONÇA, Gilson Martins. KOZICKI, Katya. COELHO, Sérgio Reis. O princípio da vulnerabilidade e as técnicas de neuromarketing: aprofundando o consumo como vontade irrefletida. Scientia Iuris, Londrina, v.18, n.1, p.135-152, jul.2014. DOI: 10.5433/21788189.2014v18n1p135. 